\title{
On the feasibility of monitoring Carbon Monxide in the lower troposphere from a constellation of Northern Hemisphere geostationary satellites. (PART 1)
}

\author{
Jérôme Barré ${ }^{1}$, David Edwards ${ }^{1}$, Helen Worden ${ }^{1}$, Arlindo Da Silva², William Lahoz ${ }^{3}$ \\ ${ }^{1}$ National Center for Atmospheric Research (NCAR), Boulder, CO, USA \\ 2 NASA Goddard Space Flight Center, Greenbelt, MD, USA \\ ${ }^{3}$ NILU, Kjeller, Norway \\ Corresponding Author: \\ Jérôme Barré, Phone: 303-497-1866, Fax: 303-497-1400 \\ barre@ucar.edu
}

\section{Abstract}

By the end of the current decade, there are plans to deploy several geostationary Earth orbit (GEO) satellite missions for atmospheric composition over North America, East Asia and Europe with additional missions proposed. Together, these present the possibility of a constellation of geostationary platforms to achieve continuous time-resolved high-density observations over continental domains for mapping pollutant sources and variability at diurnal and local scales. In this paper, we use a novel approach to sample a very high global resolution model (GEOS-5 at 7 $\mathrm{km}$ horizontal resolution) to produce a dataset of synthetic carbon monoxide pollution observations representative of those potentially obtainable from a GEO satellite constellation with predicted measurement sensitivities based on current remote sensing capabilities. Part 1 of this study focuses on the production of simulated synthetic measurements for air quality OSSEs (Observing System Simulation Experiments). We simulate carbon monoxide nadir retrievals using a technique that provides realistic measurements with very low computational cost. We discuss the sampling methodology: the projection of footprints and areas of regard for geostationary geometries over each of the North America, East Asia and Europe regions; the regression method to simulate measurement sensitivity; and the measurement error simulation. A detailed analysis of the simulated observation sensitivity is performed, and limitations of the method are discussed. We also describe impacts from clouds, showing that the efficiency of an instrument making atmospheric composition measurements on a geostationary platform is dependent on the dominant weather regime over a given region and the pixel size resolution. These results demonstrate the viability of the "instrument simulator" step for an OSSE to assess the performance of a constellation of geostationary satellites for air quality measurements. We describe the OSSE results in a follow up paper (Part 2 of this study). 
Current satellite observations of tropospheric composition made from low Earth orbit (LEO) satellites provide at best one or two measurements each day at any given location. Coverage is quasi-global but sparse, often with large uncertainties in individual measurements that limit examination of local and regional atmospheric composition over short time periods. This has hindered the operational uptake of these data for monitoring air quality and population exposure, and for initializing and evaluating chemical weather forecasts.

By the end of the current decade, there are planned geostationary Earth orbit (GEO) satellite missions for atmospheric composition over North America, East Asia and Europe, with additional missions proposed (CEOS, 2011). Together, these present the possibility of a constellation of GEO platforms to achieve continuous time-resolved high-density observations over continental domains for mapping pollutant sources and variability. The GEO geometry provides a continuous view of the part of the Earth that is below the satellite, enabling measurements many times per day that help capture the diurnal evolution of emission sources, tropospheric chemistry and pollution transport.

The planned GEO missions include the EVI-1/TEMPO (Tropospheric Emission: Monitoring of Pollution, Zoogman et al., 2014b) over USA, Sentinel 4/IRS over Europe and GEMS over Asia. Each mission has a different primary objective, but they share the common goal of monitoring pollutants for atmospheric composition and air quality and will have a common measurement capability for ozone $\left(\mathrm{O}_{3}\right)$, nitrogen dioxide $\left(\mathrm{NO}_{2}\right)$, sulfur dioxide $\left(\mathrm{SO}_{2}\right)$, formaldhyde $(\mathrm{HCHO})$ and aerosols, utilizing radiances in the ultraviolet-visible (UV-Vis) spectrum. Planned GEO observations of infrared active trace gases of relevance to air quality are currently limited to total column carbon monoxide (CO) observations from the European IRS instrument, which is originally not driven by atmospheric composition applications. However, other IR measurements that could play a part in the GEO constellation are being proposed as part of the NASA Decadal Survey GEOCAPE (GEOstationary Coastal and Air Pollution Events) mission, such as the EVI-3 CHRONOS mission (https://www2.acd.ucar.edu/chronos) that would measure CO and methane $\left(\mathrm{CH}_{4}\right)$ using heritage from the Terra/MOPITT (Measurement of Pollution in The Troposphere) instrument. Given the effect of nearby emissions and transported pollution on local air quality, MOPITT-like CO observations are a good candidate for air quality measurements on a GEO platform because the unique sensitivity of this platform to pollution in the boundary layer, as well as in the free troposphere, allows both vertical and horizontal tracking of pollution transport.

Carbon monoxide is a primary pollutant and plays an important role in tropospheric chemistry and its sources are both natural and anthropogenic. There are two main processes of CO production: incomplete combustion (e.g., industrial and urban fossil/bio fuel burning, wildfires and biomass burning); and natural chemical production from hydrocarbon oxidation. As an $\mathrm{O}_{3}$ precursor, $\mathrm{CO}$ is also important in determining the tropospheric $\mathrm{O}_{3}$ budget. The principal $\mathrm{CO}$ sink is the oxidation by hydroxyl $(\mathrm{OH})$ radicals, giving an average CO lifetime of about two months dependent on season. With these characteristics, CO serves as a tracer of 
pollution emissions and transport, and as a proxy for emissions and distributions of

91 other species co-emitted with $\mathrm{CO}$ but not easily measured. Taken together, 92 observations of the full suite of UV-Vis and IR trace gases and aerosols could provide 93 the high spatio-temporal resolution continental-scale observations of lower94 tropospheric pollution needed to monitor, forecast, and manage air quality on a daily basis (Edwards et al., 2009; Lahoz et al., 2012; Bowman et al. 2013).

Previous GEO observation simulation studies for air quality have assessed the potential capabilities of instruments covering the above three continental regions separately. Edwards et al. (2009) and Zoogman et al. (2011, 2014ab) consider the CONUS (continental US) region and demonstrate the feasibility of using observing system simulation experiment (OSSE) studies to help define quantitative trace gas measurement requirements in different spectral regions for satellite missions and to evaluate the expected performance of proposed observing strategies to test the ability of GEO satellite measurements of ozone $\left(\mathrm{O}_{3}\right)$ and CO. Claeyman et al. (2011) and Sellitto et al. (2013b) cover the European region and describe the capabilities of a concept nadir thermal infrared sensor proposed for deployment onboard a GEO platform to monitor $\mathrm{O}_{3}$ and $\mathrm{CO}$ for air quality purposes (MAGEAQ: Monitoring the Atmosphere from Geostationary orbit for European Air Quality). Lastly, Zoogman et al. (2014a) assimilate concurrent ozone and CO observations and show that geostationary measurement of CO provides significant benefit for monitoring ozone.

The goal of this study is to evaluate the impact of a future GEO constellation on global chemical weather by using the observing system simulation experiment (OSSE) technique. Here we primarily consider CO as a good chemical tracer for evaluating the impact of a GEO constellation of observations. As described by Edwards et al. (2009), chemical OSSEs provide a way of expanding case-specific sensitivity studies to assess the impact of future measurements systems. A chemical OSSE is composed of several elements (fig. 1 - see also, Timmermans et al., 2014). A nature run (NR) (1) represents the atmospheric true state. A complete OSSE needs an observation simulator (2) to sample the nature run to produce synthetic observations (3). The synthetic observations are then assimilated using a data assimilation system (4) into a second atmospheric model, the control run (CR) (5). This produces the assimilation run (AR) (6). The impact of concept instrument measurements on constraining the modeled state of the atmosphere can then be evaluated and assessed (7) by comparing the NR, CR and AR (1, 5 and 6). We describe this study in two parts. In the present paper (Part 1) we focus on the NR (1), observation simulator (2) and synthetic observations (3). A follow-up article (Part 2) will focus on assimilating the simulated measurements and assessing the synergies between the different instruments of the constellation by simulating datadenial case studies (elements 4 to 7 in fig. 1). This study presents for the first time a global GEO constellation OSSE for CO.

According to Rodgers (2000), within the remote sensing optimal estimation framework one can represent the sensitivity of the retrieved trace gas profile from a satellite measurement to the true state of the atmosphere by the averaging kernel (AK) function. For accurate observation simulations in an OSSE, we need a full radiative transfer model for radiances and their Jacobians (which represent the sensitivity of the radiance to the true atmospheric state) to compute the AKs for 
137 each atmospheric and surface scene. Since this presents a significant computational 138 burden, practical implementations of OSSEs for air quality to date have used 139 approximated observation simulators. Some have used specified constant AKs 140 (Edwards et al., 2009; Zoogman et al., 2011), or have simplified the AK variability by 141 considering only a few scene types (Claeyman et al., 2011). Sellitto et al. (2013a) 142 showed that the use of no, or limited scene dependent AK, parameterizations could 143 significantly misrepresent the sensitivity of an observing system. Sellitto et al. 144 (2013a) also recommend using comprehensive scene-dependent approximations of 145 the AKs in cases where the computational cost of a full radiative transfer model is 146 too expensive to perform an OSSE study (for example, for a GEO constellation). 147 Worden et al. (2013) address this issue by using a multiple regression analysis of 148 real satellite observations to estimate scene-dependent averaging kernels, thus 149 avoiding the use of a full radiative transfer model. This method allows the fast 150 computation of scene-dependent AKs, and the processing of a very large dataset of 151 synthetic observations in a short amount of time.

152 Due to the constraint from the NR space and time resolution, approximations 153 made to the instrument sampling and horizontal resolution cannot provide 154 information at a higher resolution than the nature run (Edwards et al., 2009). One should use high space and time resolution NRs to simulate high instrument space and time sampling. The planned missions mentioned above would provide less than $10 \mathrm{~km}$ spatial resolution at about every 1 hour. Sellitto et al. (2013b) also approximated the observation simulation by not discarding the cloud-contaminated measurements, thus leading to a possible overestimation of the GEO instrument potential to monitor tropospheric $\mathrm{O}_{3}$ and pollution features in general. One should account for cloud contamination by testing scenarios with variable instrument sampling and resolution.

In this paper we use the multiple regression analysis of Worden et al. (2013) to produce a very large data set representing a GEO constellation of synthetic observations for air quality. In section 2, we describe the very high resolution NR from the Goddard Earth Observing System Model version 5 (GEOS-5) at $7 \mathrm{~km}$ horizontal resolution. Section 3 describes the sampling methodology with details on the geostationary projection to the surface of the earth, and the multi linear regression method with its limitations for predicting averaging kernels and estimated observation errors. Section 4 investigates the impacts of clouds on the GEO constellation. The effect of horizontal resolution and sampling is discussed. Section 5 presents the measurements and a detailed analysis of the simulated observation sensitivity (e.g., averaging kernel variability). Section 6 gives a summary, conclusions and perspectives.

\section{The nature run}

The Goddard Earth Observing System Model, Version 5 (GEOS-5, Rienecker et al., 2008) is used to provide the NR. The GEOS-5 atmospheric model is a weatherand-climate model used for atmospheric analyses, weather forecasts, uncoupled and coupled climate simulations and predictions, and for coupled chemistry-climate simulations. The NR used for this study covers a 2-year global, non-hydrostatic mesoscale simulation for the period 2005-2006. In addition to standard 
184 meteorological parameters (wind, temperature, moisture, surface pressure), this 185 simulation includes 15 aerosols tracers (dust, sea salt, sulfate, black and organic 186 carbon), and $\mathrm{O}_{3}, \mathrm{CO}$ and carbon dioxide $\left(\mathrm{CO}_{2}\right)$ trace gases.

The model simulation is driven by prescribed sea-surface temperature and

Outputs at 30-minute intervals have been produced at a resolution of 0.0625 sea-ice derived at a horizontal resolution of 0.25 degrees. Biomass burning emissions of organic carbon, sulfate, $\mathrm{CO}$ and $\mathrm{CO}_{2}$ are obtained from the Quick Fire Emissions Dataset (QFED) version 2.4-r6. The basis of the QFED is the fire radiative power (top-down) approach, and it draws on the cloud correction method used in the Global Fire Assimilation System (GFAS; Kaiser et al. 2012). Anthropogenic emissions of carbon species and aerosols are largely taken from the Emissions Database for Global Atmospheric Research (EDGAR; Olivier et al., 1994), which are provided annually at a resolution of 0.1 degrees. For $\mathrm{CO}$ and $\mathrm{CO}_{2}$, EDGAR v4.2 emissions from 2005 through 2007 were used. For organic and black carbon aerosols species, Hemispheric Transport of Air Pollution (HTAP) emissions were used. degrees $(\sim 7 \mathrm{~km})$ using a cubed-sphere horizontal grid with 72 vertical levels, extending from the surface up to $0.01 \mathrm{hPa}(\sim 85 \mathrm{~km})$. All details and references concerning nature run file specifications, meteorology, chemistry and emissions can be found in the NR description documents at: http://gmao.gsfc.nasa.gov/projects/G5NR/

In this study we focus on July 2006. Figure 2 shows the CO total column provided by the NR for 15 July 2006 at 15:00 UT. This map shows the ability of the $\mathrm{NR}$ to represent the high variability of $\mathrm{CO}$ fields at a global scale. We display typical and expected CO values: very high values (above $4.10^{18}$ molecules $/ \mathrm{cm}^{2}$ ) over central Africa due to biomass burning; high values (around $3.10^{18}$ molecules $/ \mathrm{cm}^{2}$ ) over dense populated areas due to anthropogenic emissions. The NR total columns of CO also clearly show long-range transport patterns of $\mathrm{CO}$ from anthropogenic and biomass-burning sources across the oceans of the Northern Hemisphere ( $\mathrm{NH}$ ) and Southern Hemisphere (SH), respectively.

Figure 3 shows the July 2006 average of surface CO values over the three regions of interest (North America - CONUS, Europe and Eastern Asia). The NR shows realistic horizontal $\mathrm{CO}$ variability due to the very high space and time resolutions of the simulations. Emissions from cities from small to large size are clearly identifiable. Transport infrastructure such as roads (eastern US in figure 3.a) and ship routes (China sea in figure 3.c) are also visible. In this study we use the NR model output variables, both the chemical parameters (CO quantities) and the meteorological parameters (not shown), to predict averaging kernels for simulated observations in the GEO constellation. This is done for each of the CONUS, Europe and Eastern Asia regions of interest.

\section{Sampling methodology}

\subsection{Geometry of measurements}

We constructed three GEO instrument simulators over the three regions of interest defined immediately above using the methodology described in Worden et 
al. (2013). Footprints of the instruments are defined as a GEO projection on the globe. We defined $x$ (along the parallel from the sub-satellite point) and $y$ (along the meridian from the sub-satellite point) at regularly spaced scanning angles (in degrees). The GEO projection consists of projecting these angles from the GEO platform to the surface of the earth to obtain the corresponding longitudes and latitudes of the footprints. We have the following relationship between viewing angles at the satellite location and latitude, longitude position on the earth surface:

lon $=\tan ^{-1}\left(s_{1} / s_{2}\right)+$ sub_lon

$$
\text { lat }=\tan ^{-1}\left(p_{2}\left(s_{3} / s_{x y}\right)\right)
$$

where sub_lon is the sub-satellite point longitude and:

$$
s_{1}=p_{1}-s_{n} \cos x \cos y
$$

$$
s_{2}=s_{n} \sin x \cos y
$$

$$
s_{3}=-s_{n} \sin y
$$

$$
s_{x y}=\sqrt{s_{1}^{2}+s_{2}^{2}}
$$

$$
s_{d}=\sqrt{\left(p_{1} \cos x \cos y\right)^{2}-\left((\cos y)^{2}+p_{2}(\sin y)^{2}\right) p_{3}}
$$

$$
s_{n}=\frac{p_{1} \cos x \cos y-s_{d}}{(\cos y)^{2}+p_{2}(\sin y)^{2}}
$$

$\mathrm{p}_{1}=42164 \mathrm{~km}$, the altitude of a GEO platform from the center of the earth

$\mathrm{p}_{2}=1.006803$ is the ratio of the earth radius at the equator and at the pole $\left(\mathrm{p}_{2}=\right.$ $\left.\mathrm{r}_{\mathrm{eq}} / \mathrm{r}_{\mathrm{po}}\right)$.

$$
\mathrm{p}_{3}=\mathrm{p}_{1}^{2}-\mathrm{r}_{\mathrm{eq}}^{2}
$$

These equations follow from the methods provided in the technical document EUMETSAT (2011) and sketch of figure 4.d should be consulted to understand the above formulas. Projecting the regularly spaced instrument viewing angles onto the surface of the earth (figure 4.b) results in GEO instrument footprints with non-regular latitude and longitude spacing. GEO instruments then have a nonuniform horizontal resolution: the footprint density per surface area decreases as the measurements go outward from the sub-satellite point (figure 4.c). The GEOCAPE concept mission (Fishman et al., 2012) requires hourly measurements with a spatial resolution in the order of 5 to $10 \mathrm{~km}$ and a measurement domain of at least $5000 \mathrm{~km}$. Table 1 gives an overview of the characteristics of the three instruments that we call hereafter GEO-US (over CONUS), GEO-EU (over Europe) and GEO-AS (over Eastern Asia). We set the scanning angles of the three instruments to have a horizontal resolution under $10 \mathrm{~km}\left(0.1^{\circ}\right)$ in the approximate middle of the 
269 measurement domain (i.e., sub-longitude and the mean of latitudes at the sub270 longitude). Figure 4.a. shows the measurement domains of the GEO constellation. 271 Areas of coverage have different shapes due to the latitudinal extent of continents; 272 GEO-EU has more of a latitudinal extent compared to GEO-US, which has to cover a 273 wider longitude range. GEO-AS has been designed as a compromise solution and Japan.

\subsection{Carbon monoxide instrument simulator}

In this study, we assume characteristics of the CO measurements of the troposphere similar to those of the Terra/MOPITT (Measurement of Pollution in the Troposphere) instrument (Drummond, 1992). The last version of the retrieved CO product version 5 (Deeter et al., 2013) uses a multispectral approach utilizing nearvisible infrared (NIR) solar backscatter signals at 2.3 microns and thermal infrared (TIR) emission signals from the Earth surface and atmosphere at 4.6 microns. This approach provides enhanced measurement sensitivity to near-surface CO concentrations and allows the possibility of retrieving CO profile information to separate $\mathrm{CO}$ in the planetary boundary layer and free troposphere (Worden et al., 2010). This is a requirement for the GEO-CAPE concept mission (Fishman et al., 2012) and it is generally desirable for air quality space remote observations to distinguish between local emissions and transported pollution at a given location (Lahoz et al., 2012). In the case of MOPITT, the combination of the TIR and NIR radiances significantly improves the sensitivity to the lower tropospheric CO for daytime land observations. For nighttime land and day/night ocean observations, only the TIR radiances contribute to the retrieval.

The MOPITT-retrieved CO volume mixing ratios (VMRs) are on 10 pressure levels (surface, 900, 800, 700, 600, 500, 400, 300, 200, $100 \mathrm{hPa}$ ). Each retrieved level is representative of the layer content defined by the level value itself and the level above. The top most level extends from $100 \mathrm{hPa}$ to $50 \mathrm{hPa}$. The retrieved $\mathrm{CO}$ profile $y_{r}$ can be related to the true atmospheric state $y_{t}$ with the following linear relationship:

$$
\boldsymbol{y}_{r}=\boldsymbol{y}_{a}+\boldsymbol{A}\left(\boldsymbol{y}_{t}-\boldsymbol{y}_{a}\right)+\boldsymbol{\varepsilon}
$$

In Eq. (3) $y_{\boldsymbol{t}}$ is the true atmospheric CO profile state (in $\log _{10}(\mathrm{VMR})$ ) and $\boldsymbol{y}_{a}$ is the apriori state vector (in $\log _{10}(\mathrm{VMR})$ ) derived from a monthly mean climatological profile from the MOZART-4 (Model for Ozone and Related chemical Tracers, version 4) chemical transport model (Emmons et al., 2010). The random error $\varepsilon$ (in $\left.\log _{10}(\mathrm{VMR})\right)$ is simulated using the retrieval noise, and $\boldsymbol{A}$ is the retrieval AK matrix (see section 3.3). (The $\boldsymbol{y}_{r}$ retrieved profile obtained is then converted from $\log _{10}$ (VMR) to VMR for the final data product).

Figure 5 shows two representative MOPITT AKs. The sensitivity of the MOPITT instrument to near-surface $\mathrm{CO}$ varies according to different surface types and atmospheric conditions. The left panel of Fig. 5 shows a typical AK for a daytime measurement over land with enhanced sensitivity toward the surface. The right panel of Fig. 5 shows a typical AK for a TIR-only ocean or nighttime measurement 
over land with low sensitivity in the lowermost troposphere. A useful quantity

317 indicating the information content of a measurement is the degrees of freedom for 318 signal (DFS), given by $\operatorname{tr}(\boldsymbol{A})$ (Rodgers, 2000). Higher DFS values indicate more 319 sensitivity of the retrieval to the true profile.

To diagnose the sensitivity of the measurement to the lowest layers, DFS can

\subsection{Simulated retrieval method.}

Worden et al. (2013) investigated the CO retrieval error resulting from the use of a single average $\mathrm{AK}$ in an observation simulator compared using the true retrieval AKs. They further developed a scene-dependent AK prediction tool capable of approximating the true AK with a significant reduction in retrieved $\mathrm{CO}$ error compared to using a single average AK. This AK prediction tool allows us to produce a large amount of simulated data over months in an efficient manner. One month of data for a GEO constellation (i.e,. around 200 million profiles) can be produced in less than 12 hours.

The method of Worden et al. employs a multiple regression approach for deriving scene dependent AKs using predictors based on state parameters from the NR. The main parameters used are: CO concentration, temperature, specific humidity and pressure (see table 2). The method is based on the computation of the singular value decomposition (SVD) of the AK matrix. Given an AK matrix $\boldsymbol{A}$, we compute the SVD by means of:

$$
\boldsymbol{A}=\boldsymbol{U} \Lambda \boldsymbol{V}^{T}
$$

where the columns of $\boldsymbol{U}$ and $\boldsymbol{V}$ are the left and right singular vectors respectively, and the elements of $\boldsymbol{\Lambda}$ (a diagonal matrix) are the singular values. Since the first two singular vectors account for $95 \%$ of the variability of MOPITT CO AKs on average and the first three singular vectors account for $99.995 \%$, the method retains the first three ranked singular vectors. For a complete description of the SVD technique, numerical examples and software used please refer to Worden et al., 2013. We then calculate the three first singular vectors and values using multiple regression. For example,

$$
U_{i j}=c_{i j}+\sum_{k=1}^{N} a_{i j k} x_{j k}
$$

with dimensions of: $i$ singular vectors, $j$ pressure levels, and $k$ predictors. The parameters are: $c$, a constant; $a$, regressions coefficients; and $x$, predictors. We used twelve predictors $(N=12)$ and have defined eleven different training sets (containing 
the $\boldsymbol{a}$ coefficients) for the geographical regions of interest. Only a single training set can be used in the regression calculation. The predictors and training sets are listed in Table 2. Worden et al. (2013) selected the predictors based on their importance in the regression technique for parameterizing MOPITT forward model transmittances of Edwards et al. (1999). The training sets are derived from a multi linear fit using real MOPITT observations. The training set period is the entire year 2006. Once an AK matrix $\mathbf{A}$ is predicted, the simulated observation profile from the NR can be computed using the retrieval equation:

$$
\boldsymbol{y}_{r}=\boldsymbol{y}_{a}+\boldsymbol{A}\left(\boldsymbol{y}_{N R}-\boldsymbol{y}_{a}\right)+\boldsymbol{\varepsilon}
$$

with $\boldsymbol{y}_{N R}$, the NR profile sampled at the MOPITT vertical resolution, replacing the true state profile $\boldsymbol{y}_{t}$ in equation 3. Because MOPITT retrieved values express a CO quantity over a pressure layer, we compute a weighted average using the pressure thickness of the GEOS-5 vertical CO levels mapped onto the MOPITT grid to produce $\boldsymbol{y}_{N R}$.

\subsection{Training set method limitations}

In section 3.3 we applied the method described Worden et al. (2013), to reconstruct the averaging kernel matrix. In order to utilize the multi linear regression (equation 5), we need pre-calculated coefficients $\left(\mathbf{a}_{0, \mathrm{~N}}\right)$ from a multiregression fit derived from real MOPITT observations, that we call training sets given in Table 2. In some cases, mostly over the CONUS and Asian megacities, very high CO profile concentrations and total CO column amount values can extend beyond the boundary values of the data set used to build the training set and hence beyond the boundary values of the training set itself. Because of the near linear relationship between predictors and predicted AKs (equation 4 and 5), using predictors from the model with values that are outside the training set distributions may lead to unphysical averaging kernel values, e.g., strong negative values or values above unity. This is most likely the case for the CO predictors (CO profile and CO total column). In order to prevent predictors that are outside the training set range and not to discard a significant amount of simulated observation over polluted areas we reduce the CO profile predictor as follows. We calculate the mean $(\mu)$ and standard deviation $(\sigma)$ of the CO profile training sets. If the predicted CO profile values (p) are above $\mu+2 \sigma$, the new predictor ( $\left.p^{\prime}\right)$ is then calculated as follows:

$$
p^{\prime}=(1-\gamma)(\mu+2 \sigma)+\gamma p
$$

where $\gamma$ is a weighting coefficient ranging between 0 and 1 . Then the scaled CO profile is used to recalculate related CO predictors ( $\mathrm{CO}$ column, $\operatorname{Cos}\left(\theta_{\mathrm{sza}}\right) / \log _{10} \mathrm{CO}(\mathrm{z})$ and $\mathrm{dT}(\mathrm{z})) / \log _{10} \mathrm{CO}(\mathrm{z})$ ). This allows the simulator to produce reasonable variability in measurement sensitivity while still including the high CO cases and without generating unphysical averaging kernels. Sensitivity tests during extreme pollution events have shown that using $\gamma>0.2$ produces an unacceptably high frequency of 
409 unrealistic averaging kernel functions. In order to have a robust observation

410 simulator which does not produce unphysical averaging kernel values we use $\gamma=0.1$.

\subsection{Simulated error method}

The regression method described above does not account for simulating measurement error (represented by the retrieval error covariance matrix) and retrieval noise. In order to simulate the error terms, we use the relationships between the AK matrix and the associated retrieval errors terms (Rodgers, 2000). The associated retrieval noise $\varepsilon$ is defined using the retrieval noise covariance matrix $\boldsymbol{C}_{n}$, derived from the retrieval error covariance matrix $\boldsymbol{C}_{x}$. Where $\varepsilon$ is the vector containing the square root of the diagonal elements of $\boldsymbol{C}_{n}$, and $y_{\text {err }}$ the vector containing the square root of the diagonal elements of $\boldsymbol{C}_{x}$. The retrieval error covariance matrix $\boldsymbol{C}_{x}$ can be decomposed as the sum of two matrices (Deeter et al. 2011):

- A smoothing error covariance matrix $\boldsymbol{C}_{s}$ that describes the expected error arising from differences between the true profile and retrieved profile, and which are due to the characteristics of the weighting functions and the influence of the a priori covariance matrix.

- A retrieval noise error covariance matrix $\boldsymbol{C}_{n}$ that quantifies the expected errors due to errors in the radiances.

Then

$$
\boldsymbol{C}_{x}=\boldsymbol{C}_{s}+\boldsymbol{C}_{n}
$$

with $\boldsymbol{C}_{s}$ approximated using the a priori covariance matrix $\boldsymbol{C}_{a}$, as follows

$$
\boldsymbol{C}_{s}=(\boldsymbol{I}-\boldsymbol{A}) \boldsymbol{C}_{a}(\boldsymbol{I}-\boldsymbol{A})^{T}
$$

and $\boldsymbol{C}_{x}$ directly calculable from $\boldsymbol{C}_{a}$ and $\boldsymbol{A}$

$$
\boldsymbol{C}_{x}=(\boldsymbol{I}-\boldsymbol{A}) \boldsymbol{C}_{a}
$$

so that

$$
\boldsymbol{C}_{n}=\boldsymbol{C}_{x}\left(\boldsymbol{I}-(\boldsymbol{I}-\boldsymbol{A})^{\boldsymbol{T}}\right)
$$

$\boldsymbol{C}_{n}$ is mostly lower than $\boldsymbol{C}_{s}$ but not negligible (see section 5.2 and figure 11). Relatively to $\boldsymbol{C}_{x}, \boldsymbol{C}_{n}$ will increase if $\boldsymbol{C}_{s}$ decrease (if $\boldsymbol{A}$ tends to be the identity $\boldsymbol{I}$ ). We define $\boldsymbol{C}_{a}$ as for the MOPITT v4 and v5 products (Deeter et al., 2010). The a priori covariance matrix $\boldsymbol{C}_{a}$ incorporates the same variance value $C_{0}$ at all levels, with a constant correlation height $\mathrm{P}_{c}$ over a pressure level $p$ defining the off-diagonal 455 
with $\mathrm{P}_{\mathrm{c}}=100 \mathrm{hPa}$ and $\mathrm{C}_{0}=\left(0.3 \log _{10} \mathrm{e}\right)^{2}$. In order to simulate the random error $\varepsilon$, we

$$
C_{a, i j}=C_{0} e^{-\left(\left(p_{i}-p_{j}\right) / P_{c}\right)^{2}}
$$

$$
\boldsymbol{\varepsilon}=\boldsymbol{y}_{r} \boldsymbol{C}_{n}^{1 / 2} \circ \mathcal{N}(0, \boldsymbol{I})
$$

where $\circ$ denotes the Schur product and $\mathcal{N}(0, I)$ a matrix following a normal distribution of means equal 0 and standard deviation equal the identity matrix $I$. We also calculate the retrieval error profile as follows:

$$
y_{e r r, i}=y_{r, i} C_{x, i, i}^{1 / 2}
$$

Because the smoothing error $\boldsymbol{C}_{s}$ mostly dominates on the error budget (equation 8), the impact of the random error $\varepsilon$ is low compared to the retrieval error profile and hence the accuracy of the retrievals are not significantly impacted.

\section{Impact of clouds}

Under cloudy conditions, the simplest approach for MOPITT-like measurements on a GEO platform would be simply to discard cloudy pixels and not perform retrievals. It is thus important to assess the impact of the cloud coverage on GEO measurements. In this study, a scene is considered clear when the interpolated cloud fraction from the NR is lower than $5 \%$ of a single footprint. This is the clearsky condition used operationally with real MOPITT measurements. Cloud contaminated footprints with greater than $5 \%$ of cloud fraction would be discarded. Clouds properties are not used to predict AK variability. Figure 6 presents the ratio of cloud free pixels, over the month of July 2006 for the constellation. The ratio of cloud free pixels is the number of cloud free observations divided by the total number of possible observations (i.e., one per hour during one month) for a given pixel. Figure 9 gives an idea of instantaneous instrument coverage with a 5\% cloud fraction threshold. The GEO-EU displays very few cloud-contaminated areas whereas the GEO-AS has very few cloud free areas.

The cloud-free ratio geographical distribution shows differences between intra- and inter-continental regions. On average, GEO-EU has the highest ratio $(60 \%)$ followed by GEO-US (40\%) and GEO-AS (20\%). Strong variations of the ratio are also observed for different weather regimes within each measurement domain. Mediterranean weather regimes such as western CONUS and the entire Mediterranean basin exhibit higher ratios, above 80\%. Conversely, oceanic, subtropical and tropical regimes such as northern Europe, southern CONUS and southeastern Asia have lower ratios, below 20\%. Over the GEO-AS field of view, Korea and Japan exhibit very low ratios around 10\% due to East Asian monsoon effects that provide persistent convective cloud coverage.

The value of the cloud free ratio depends on the spatial resolution of the observation (pixel size) and the cloud fraction threshold used. Figure 7 displays results of sensitivity tests on pixel size and cloud fraction threshold. We assume that 
the lowest pixel size simulated is $7 \mathrm{~km}$ due to the model horizontal resolution. We

503 can then increase the pixel size by averaging contiguous grid cells. It is shown here

504 that with a given cloud fraction threshold, increasing the pixel size reduces the

505 average cloud free ratio. We perform tests for varying cloud fraction thresholds to

506 calibrate the assimilated data product. Variations of the cloud free ratio following

507 variations in the cloud fraction threshold and the pixel size show the same patterns

508 (but with a different range of values) for the three instruments of the constellation.

509 To explain these patterns we display a specific case (figure 8) as an example

510 of how the observed coverage changes with the two varying parameters. The case

511 study presented shows two typical horizontal cloud structures: one of high

512 granularity located over the eastern part of the plot, which is identified as

513 convective structures, and the other of low granularity located on the northwest

514 part of the plot, which is identified as a cold air front. Over low granularity areas,

515 decreasing the cloud fraction threshold will not increase the cloud-contaminated

516 area as much as it does over the high granularity areas. As an idealized example, one

517 can imagine adding pixels around four single separated sparse pixels (a granular

518 structure) and adding a pixel around a four-by-four pixel area (a non-granular

519 structure). In the first case, there will be 8 pixels around each of the 4 original

520 pixels, making a total of 32 additional pixels. In the second case 12 additional pixels

521 will surround a 2 by 2 square. The increase in area will be larger with the granular

522 structure than with the non-granular structure.

523 In the more realistic case of our observation simulations, granularity can

524 vary at different scales and at different times. We found that adjusting the cloud

525 fraction threshold to $20 \%$ for a $42 \mathrm{~km}$ pixel size gives comparable statistics of cloud

526 coverage as with the 5\% threshold for a $7 \mathrm{~km}$ pixel size (see section 5.3 and figure

527 12).

528

529

530

531

532

533

534

535

536

537

538

539

540

541

542

543

544

545

546

547

\section{Simulated GEO constellation measurements}

\subsection{Simulated sensitivity analysis}

Figure 9 displays the maps of sampled Surface-700 hPa NR and retrieved partial columns and associated $\mathrm{DFS}_{0,3}$ for the GEO constellation. Looking at $\mathrm{DFS}_{0-3}$ maps first shows that the observation simulator reproduces the variability of measurement sensitivity over the satellite measurement domains. The maps are snapshots during daytime, and show strong differences in $\mathrm{DFS}_{0-3}$ between sea and land due to the different AK training sets used. The land training set simulates multispectral (TIR+NIR) retrieval AKs in contrast to the sea training set that simulates TIR-only retrievals. The $\mathrm{DFS}_{0,3}$ values between land and sea surfaces are in agreement with figure 5: instrument sensitivities over land are generally higher than over sea, because of the availability of multi-spectral simulated retrievals. DFS variability over land, or over sea only, is also simulated using the multi-regression fit as described in section 3.3. To describe this variability, we will focus on the analysis over land. The most obvious variations of $\mathrm{DFS}_{0,3}$ follow orography. The main reason is the reduction in the number of retrieved levels if surface pressure is lower than, e.g., $900 \mathrm{hPa}$. For a constant number of retrieved levels, the variation of the surface 548 level layer thickness also plays a significant role (represented by the dP predictor; 
549 see table 2), and a thinner surface layer will contribute less retrieval sensitivity. 550 Variations of $\mathrm{DFS}_{0,3}$ can also be correlated to the CO amount in the NR. This 551 variability is represented with the CO total column and CO profile predictors. CO 552 abundance is a strong predictor of sensitivity due to the use of $\log _{10}$ (VMR) retrievals 553 in MOPITT with corresponding weighting functions that have increasing magnitude 554 for increasing VMR (Worden et al., 2013). Finally, the temperature profile and thermal contrast (dT) play a significant role in the $\mathrm{DFS}_{0-3}$ variability, as expected for the TIR contribution in a multispectral instrument. While $\mathrm{DFS}_{0-3}$ depends more on predictors such as CO column and $\mathrm{dP}$, all of the predictors in Table 2 add information to the regression fit, as tested in Worden et al. (2013).

Figure 10 shows scatter plots of $\mathrm{DFS}_{0-3}$ versus the main DFS variability drivers, i.e., parameters mentioned above such as CO concentration, dP and dT. 561 Night and day values are displayed (blue and red, respectively) showing the 562 expected increase of sensitivity during day (simulating a multispectral retrieval) 563 compared to night (simulating a TIR-only retrieval). For each region, using an 564 alternation of day training sets and night training sets, designed to produce 565 multispectral and TIR-only retrieval AKs, respectively, then simulates a diurnal cycle of sensitivity. Correlation of $\mathrm{DFS}_{0-3}$ with predictors gives an indication of which variables in the NR true state will drive measurement sensitivity. However, this is not a deterministic result since actual sensitivity depends on all the predictors, together with the distributions of those

variables as compared to the training set distributions, indicated by the lines in Figure 10. Variations in the dependence on predictors can be seen by the different distributions in Figure 10 for CONUS, Europe and Asia. Over Asia and Europe, overall CO concentrations from NR show significantly lower as compared to the training set mean. For Asia, scatter plots do not show any clear dependence between DFS $_{0-3}$ and $\mathrm{CO}$ concentrations. For Europe, the dependence is more marked during daytime. Lower CO predictor values compared to training set mean might lead to underestimation of $\mathrm{DFS}_{0-3}$, however it fits a realistic range of values (from 0.25 to $0.5)$.

\subsection{NR sampling and error budget}

The difference between the NR CO and the retrieved CO shows higher NR values than in the simulated retrievals (fig. 9). Retrieved values can be close to the NR if sensitivity (DFS) is high enough and/or the a priori CO profile is close enough to the NR. Cases with strong CO plumes in the NR can be identified in figure 9 over Asia (around $35^{\circ} \mathrm{N}$ and $115^{\circ} \mathrm{E}$ ) and over Europe (around $5^{\circ} \mathrm{E}$ and $55^{\circ} \mathrm{N}$ ). In the Asian case, the plume is very well detected in the synthetic retrieval, because over land GEO-AS has a DFS 0,3 above 0.5 and a priori profile concentrations close to the NR profile (not shown). In the European case, plumes are barely detected because over sea the GEO-EU has $\mathrm{DFS}_{0,3}$ below 0.3 and the a priori profile concentrations are far from NR values. In general, retrieved CO concentrations are lower than the NR CO concentration because a priori values are lower than NR values. In certain cases (see fig. 9 for Asia around $110^{\circ} \mathrm{E}$ and $35^{\circ} \mathrm{N}$ ), the opposite is observed; a priori concentrations are higher than the NR. The a priori profile, sampled from a lower resolution MOZART-4 climatology (see section 3.2) does not capture the specific NR 
high-resolution features. Conversely, polluted areas are represented as relatively high CO over broad area, which can produce cases where $y_{a}$ is higher than $y_{t}$.

Figure 11 left panels show scatter plots of NR CO partial columns (Xt) versus

This can be estimated for this study since we are assuming the NR is the true state. However, for real observations it is not possible to estimate the actual smoothing covariance error matrix. Therefore, use of the method described in section 3.5 is more realistic, and will provide reasonable error estimates in most cases since Xs has generally lower values than Xe.

\subsection{Reduced resolution simulated observations}

In part II of this study, we will assimilate the simulated GEO-constellation into a global model. We will use the global chemistry - climate model CAM-Chem, including its full chemical scheme (Lamarque et al., 2012). State-of-the-art global atmospheric chemical models do not have high horizontal resolution. In this second part of the study, we use a $0.9^{\circ}$ by $1.25^{\circ}$ resolution model configuration. Since the resolutions of the NR and the simulated observations are much finer than the CAMChem resolution, we will use the reduced resolution NR $\left(0.5^{\circ}\right.$, i.e., $42 \mathrm{~km}$ approximately). The reduced NR simulations are the same as the native NR simulations, but the horizontal resolution has been reduced a posteriori (see Da Silva et al., 2014).

Figure 12 displays the reduced resolution $(42 \mathrm{~km})$ simulated observations. As explained in section 3.5, because the model resolution is $42 \mathrm{~km}$ we assume that the pixel size has the same size. To generate an appropriate sampling according to 
643 the pixel resolution, we divide by a factor of 5 the number of latitude and longitude 644 pixels provided in the table. The left panels show the average surface-700hPa 645 retrieved CO column for July 2006. The right panels show the cloud free ratio for 646 July 2006. For the cloud fraction threshold, we use $20 \%$ to keep the same cloud free 647 ratio as for the high-resolution observation simulation, as explained in section 3.5. 648 Cloud free ratio maps (figure 12) at low resolution are then very similar to the same 649 maps at high resolution (figure 6).

\section{Conclusion}

This paper is Part 1 of a two-part study. Here, we demonstrate the feasibility of simulating a GEO constellation for air quality monitoring, with a focus on CO. Three potential instruments are simulated covering the three most populated and polluted areas of the world: Continental US (CONUS), Western Europe and Easter Asia. We use very high-resolution output $\left(0.06^{\circ}\right.$, i.e., $\sim 7 \mathrm{~km}$ horizontal resolution) from the GEOS-5 model as a NR to simulate a MOPITT-like instrument. Instead of using a full radiative transfer model to simulate the instrument vertical retrieval sensitivity as defined by the AK, we use a novel method described by Worden et al., (2013). This method employs multi-linear regression using predictors (from the NR) and training set coefficients (from real MOPITT data) to produce scenedependent AKs, thus allowing a very fast computation of the instrument synthetic measurement dataset. Thus, we avoid the computational burden of using a full radiative transfer model, allowing the generation of one month of GEO constellation 667 data in less than 12 hours. This makes simulation of the GEO constellation 668 measurement computationally feasible. The main conclusions of this work are as 669 follows:

1. Instead of using the model resolution as the instrument pixel resolution, and the defined field of view as a simple latitude/longitude rectangle, we present a method to simulate the data using a GEO projection. This gives accurate GEO instrument spatial resolutions and fields of view that vary with latitude and longitude.

2. This paper extends application of the Worden et al., (2013) averaging kernel (AK) prediction method. Realistic variations of potential GEO instrument vertical retrieval sensitivities are simulated. Instrument sensitivities depend on predictors and the main drivers are: surface pressure, CO profile and temperature profile. Rather than using an average AK for fast computation, the observation simulator presented here is able to provide fast computation of AK variability (and its associated retrieval error covariance matrix) at the same time.

3. We discuss limitations of the method used for this study. The very high CO concentrations occurring in the NR over very polluted areas often overreach the training set statistical coverage. In this situation, we use a tuning method to reduce the amplitude of CO variations in the NR.

4. To make the observation simulations as realistic as possible, we account for the impact of clouds. Cloud contamination in the observations is strongly 
Acknowledgements: This work was partly supported by NASA grants NNX09AH03G S02, NNX11AI10G and NNX11AG63G. The National Center for Atmospheric Reserch is sponsored by the National Science Foundation.

\section{References:}

Bowman, K. W.: Toward the next generation air quality monitoring: Ozone. Atmospheric Environment 80: 571-583. 10.1016/j.atmosenv.2013.07.007. 2013.

Committee on Earth Observation Satellites (CEOS), Atmospheric Composition Constellation: A Geostationary Satellite Constellation for Observing Global Air Quality: An International Path Forward, http://old.ceos.org/images/ACC/AC_Geo_Position_Paper_v4.pdf, April 12, 2011

Claeyman, M., $\quad$ Attié, J.-L., $\quad$ Peuch, V.-H., $\quad$ El Amraoui, L., $\quad$ Lahoz, W. A., $\quad$ Josse, B., Ricaud, P., von Clarmann, T., Höpfner, M., Orphal, J., Flaud, J.-M., Edwards, D. P., Chance, K., Liu, X., Pasternak, F., and Cantié, R.: A geostationary thermal infrared 
sensor to monitor the lowermost troposphere: $\mathrm{O}_{3}$ and $\mathrm{CO}$ retrieval studies, Atmos.

736 Meas. Tech., 4, 297-317, doi:10.5194/amt-4-297-2011, 2011.

737 da Silva, A.M., W. Putman and J. Nattala: File Specification for the 7-km GEOS-5

738 Nature Run, Ganymed Release (Non-hydrostatic 7-km Global Mesoscale Simulation).

739 GMAO Office Note No. 6 (Version 1.0), 176 pp, available from

740 http://gmao.gsfc.nasa.gov/pubs/office_notes. 2014.

741 Deeter, M. N., et al., The MOPITT version 4 CO product: Algorithm enhancements,

742 validation, and long-termstability, J. Geophys. Res., 115, D07306,

743 doi:10.1029/2009JD013005. 2010.

Deeter, M. N., H. M. Worden, J. C. Gille, D. P. Edwards, D. Mao, and J. R. Drummond, MOPITT multispectral CO retrievals: Origins and effects of geophysical radiance errors, J. Geophys. Res., 116, D15303, doi:10.1029/2011JD015703. 2011.

Deeter, M. N., Martinez-Alonso, S., Edwards, D. P., Emmons, L. K., Gille, J. C., Worden, H. M., Pittman, J. V., Daube, B. C., and Wofsy, S. C.: Validation of MOPITT Version 5 thermalinfrared, near-infrared, and multispectral carbon monoxide profile retrievals for 2000-2011, J. Geophys. Res.-Atmos., 118, 1- 16, doi:10.1002/jgrd.50272, 2013.

Drummond, J. R., Measurements of Pollution in the Troposphere (MOPITT), in The Use of EOS for Studies of Atmospheric Physics, edited by J. C. Gille and G. Visconti, pp. 77-101, North-Holland, New York. 1992.

Edwards, D. P., Halvorson, C. M., and Gille, J. C.: Radiative transfer modeling for the EOS Terra satellite Measurement of Pollution in the Troposphere (MOPITT) instrument, J. Geophys. Res., 104, 16755-16775, 1999.

Edwards, D. P., Arellano Jr., A. F., and Deeter, M. N.: A satellite observation system simulation experiment for carbon monoxide in the lowermost troposphere, J. Geophys. Res., 114, D14304, doi:10.1029/2008JD011375, 2009.

Emmons, L. K., et al., Description and evaluation of the Model for Ozone and Related chemical Tracers, version 4 (MOZART-4), Geosci. Model Dev., 3, 43-67. 2010.

EUMETSAT, The EUMETSAT Satellite Application Facility on Land Surface Analysis, Product User Manual, Issue 2.6 v2, Météo-France-CNRM. 2011.

Fishman, J., et al., The United States' Next Generation of Atmospheric Composition and Coastal Ecosystem Measurements: NASA's Geostationary Coastal and Air Pollution Events (GEO-CAPE) Mission. Bull. Amer. Meteor. Soc., 93, 1547-1566. doi: http://dx.doi.org/10.1175/BAMS-D-11-00201.1. 2012

Kaiser, J. W. , A. Heil, M. O. Andreae, A. Benedetti, N. Chubarova, L. Jones, J.-J. Morcrette, M. Razinger, M. G. Schultz, M. Suttie, and G. R. van der Werf, 2012: 
780 Biomass burning emissions estimated with a global fire assimilation system based 781 on observed fire radiative power. Biogeosciences, 9(1):527-554, 2012. doi: 782 10.5194/bg-9-527-2012.

Lahoz, W. A., et al., Monitoring Air Quality from Space: The Case for the Geostationary Platform. Bull. Amer. Meteor. Soc., 93, 221-233. doi: http://dx.doi.org/10.1175/BAMS-D-11-00045.1. 2012

Lamarque, J.-F., $\quad$ Emmons, L. K., $\quad$ Hess, P. G., Kinnison, D. E., Tilmes, S., Vitt, F., Heald, C. L., Holland, E. A., Lauritzen, P. H., Neu, J., Orlando, J. J., Rasch, P. J., and Tyndall, G. K.: CAM-chem: description and evaluation of interactive atmospheric chemistry in the Community Earth System Model, Geosci. Model Dev., 5, 369-411, doi:10.5194/gmd-5-369-2012, 2012.

Olivier, J., A. Bouwman, C. Maas, and J. Berdowski: Emission Database for Global Atmospheric Research (EDGAR). Environ. Monit. Assess., 31, 93-106. 1994.

Rienecker et al., The GEOS-5 Data Assimilation System- Documentation of Versions 5.0.1, 5.1.0, and 5.2.0, Technical Report Series on Global Modeling and Data Assimilation, Volume 27, NASA/TM-2008-104606, Vol. 27, 2008

Rodgers, C. D.: Inverse Methods for Atmospheric Sounding, Theory and Practice, World Scientific, Singapore, New Jersey, London, Hong Kong, 2000.

Sellitto, P., Dufour, G., Eremenko, M., Cuesta, J., Peuch, V.-H., Eldering, A., Edwards, D. P., and Flaud, J.-M.: The effect of using limited scene-dependent averaging kernels approximations for the implementation of fast Observing System Simulation Experiments targeted on lower tropospheric ozone, Atmos. Meas. Tech. Discuss., 6, 2413-2448, doi:10.5194/amtd-6-2413-2013, 2013a.

Sellitto, P., Dufour, G., Eremenko, M., Cuesta, J., Forêt, G., Gaubert, B., Beekmann, M., H Peuch, V., and Flaud, J.-M.: Monitoring the lowermost tropospheric ozone with thermal infrared observations from a geostationary platform: performance analyses for a future dedicated instrument, Atmos. Meas. Tech. Discuss., 6, 6445-6490, doi:10.5194/amtd-6-6445-2013, 2013b.

Timmermans, R., W.A. Lahoz, J.-L. Attié, V.-H. Peuch, L. Curier, D. Edwards, H. Eskes, and P. Builtjes : Observing System Simulation Experiments for Air Quality. Atmos. Env., submitted. 2014

Worden, H. M., M.N. Deeter, D. P. Edwards, J. C. Gille, J. R. Drummond, and P. Nedelec, Observations of near-surface carbon monoxide from space using MOPITT multispectral retrievals, J. Geophys. Res. Atmos., doi:10.1029/2010JD014242. 2010.

Worden, H. M., Edwards, D. P., Deeter, M. N., Fu, D., Kulawik, S. S., Worden, J. R., and Arellano, A.: Averaging kernel prediction from atmospheric and surface state parameters based on multiple regression for nadir-viewing satellite measurements 
827 of carbon monoxide and ozone, Atmos. Meas. Tech., 6, 1633-1646, doi:10.5194/amt828 6-1633-2013, 20, 2013.

829

830 Zoogman, P., Jacob, D. J., Chance, K., Zhang, L., Le Sager, P., Fiore, A. M., Eldering, A., 831 Liu, X., Natraj, V., and Kulawik, S. S.: Ozone Air Quality Measurement Requirements 832 for a Geostationary Satellite Mission, Atmos. Environ., 45, 7143-7150, 833 doi:10.1016/j.atmosenv.2011.05.058, 2011.

834

Zoogman, P., D.J. Jacob, K. Chance, H.M. Worden, D.P. Edwards, L. Zhang, Improved 836 monitoring of surface ozone air quality by joint assimilation of geostationary 837 satellite observations of ozone and CO. Atmospheric Environment, 84, 254-261, 838 2014a.

839

840 Zoogman, P., D.J. Jacob, K. Chance, X. Liu, A. Fiore, M. Lin, K. Travis, Monitoring high841 ozone events in the US Intermountain West using TEMPO geostationary satellite 842 observations. Atmospheric Chemistry and Physics, 14, 6261-6271, 2014b.

843

844

845

846

847

848

849

850

851

852

853

854

855

856

857

858

859

860

861

862

863

864

865

866

867

868

869

870

871

872

873 


\begin{tabular}{|c|c|c|c|}
\hline & GEO-AM & GEO-EU & GEO-AS \\
\hline Sub_lon & $-97^{\circ}$ & $8.4^{\circ}$ & $120^{\circ}$ \\
\hline Number x pixels & 500 & 400 & 400 \\
\hline Number y pixels & 230 & 250 & 200 \\
\hline$x_{\max }$ & $3.5^{\circ}$ & $2.4^{\circ}$ & $3.3^{\circ}$ \\
\hline$x_{\min }$ & $-3.5^{\circ}$ & $-2.4^{\circ}$ & $-3.3^{\circ}$ \\
\hline$y_{\max }$ & $7.2^{\circ}$ & $8.2^{\circ}$ & $6.7^{\circ}$ \\
\hline$y_{\min }$ & $4.2^{\circ}$ & $5.7^{\circ}$ & $3.5^{\circ}$ \\
\hline
\end{tabular}

880

Table 1. GEO-constellation instrument specifications: satellite position,

881

882

883

884

885

886

\begin{tabular}{|c|c|}
\hline Predictors & Training sets \\
\hline$\theta_{\text {sza }}$ & North Hemisphere Ocean (TIR) \\
\hline Emissivity & CONUS Day (Psrf $>900 \mathrm{hPa}, \mathrm{TIR}+\mathrm{NIR})$ \\
\hline Latitude & CONUS Night (Psrf $>900 \mathrm{hPa}, \mathrm{TIR})$ \\
\hline Surface temperature & Europe Day (Psrf $>900 \mathrm{hPa}, \mathrm{TIR}+\mathrm{NIR})$ \\
\hline $\mathrm{dP}=\mathrm{P}_{\text {surface }}-\mathrm{P}_{\text {ref }}{ }^{*}$ & Europe Night (Psrf $>900 \mathrm{hPa}, \mathrm{TIR})$ \\
\hline CO column & Eastern Asia Day (Psrf $>900 \mathrm{hPa}, \mathrm{TIR}+\mathrm{NIR})$ \\
\hline Water Vapor Q(z) & Eastern Asia Night (Psrf $>900 \mathrm{hPa}, \mathrm{TIR})$ \\
\hline $\mathrm{CO}(\mathrm{z})$ & N.H. Mountains Day $(900 \mathrm{hPa}>\mathrm{Psrf}>800 \mathrm{hPa}$, TIR+NIR) \\
\hline Thermal contrast dT(z)=(Tsrf-T(z)) & N. H. Mountains Day (800hPa $>$ Psrf $>700 \mathrm{hPa}$, TIR) \\
\hline $\mathrm{dT}(\mathrm{z})^{2}$ & N.H. Mountains Night $(900 \mathrm{hPa}>\mathrm{Psrf}>800 \mathrm{hPa}, \mathrm{TIR}+\mathrm{NIR})$ \\
\hline $\operatorname{Cos}\left(\theta_{\text {sza }}\right) / \log _{10} \mathrm{CO}(\mathrm{z})$ & N. H. Mountains Night $(800 \mathrm{hPa}>$ Psrf $>700 \mathrm{hPa}, \mathrm{TIR})$ \\
\hline $\mathrm{dT}(\mathrm{z})) / \log _{10} \mathrm{CO}(\mathrm{z})$ & \\
\hline
\end{tabular}

889 Table 2. Left: List of predictors, right: List of the different training sets used to 890 produce the geostationary constellation CO measurements. TIR and NIR state 891 if the training set simulates multispectral or TIR-only retrievals (see text for 


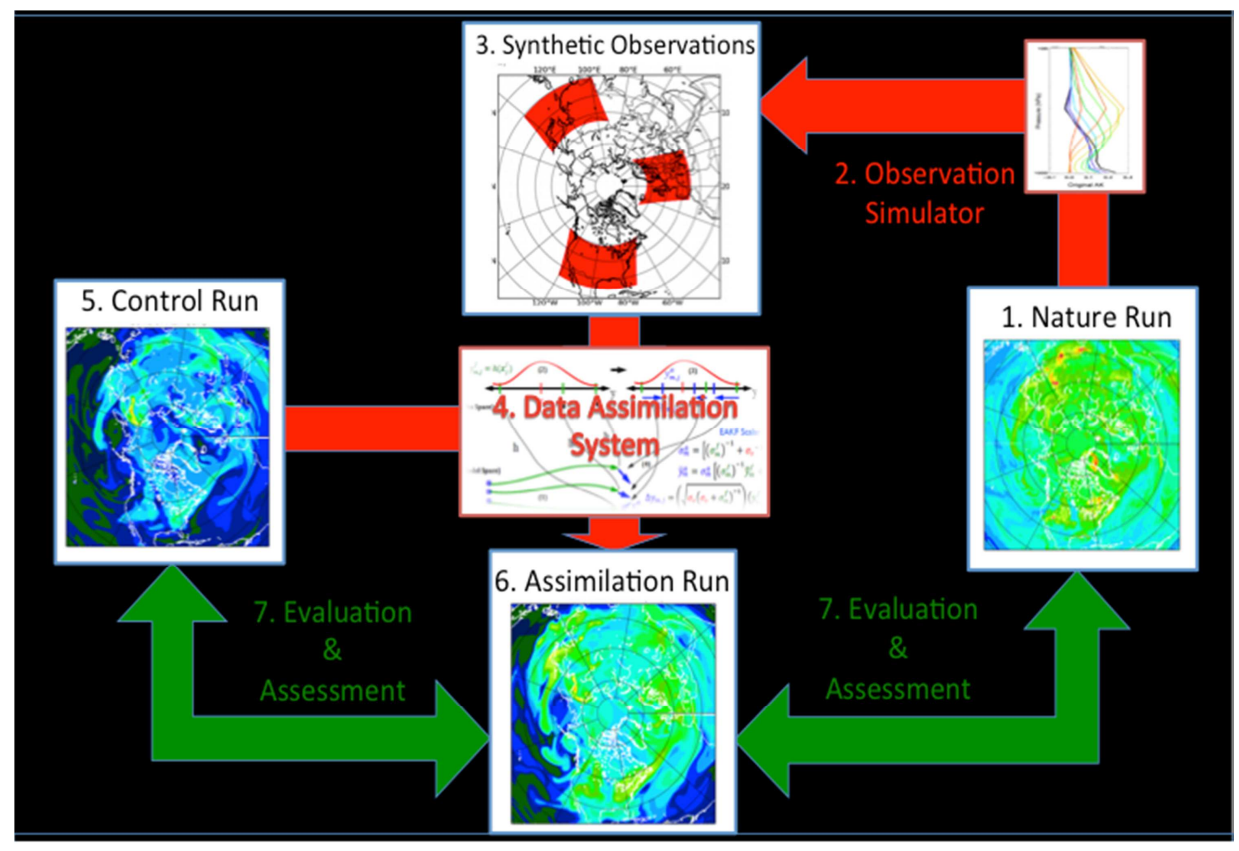

Figure 1. The chemical OSSE framework. See text for details.

910

911

912

913

914 

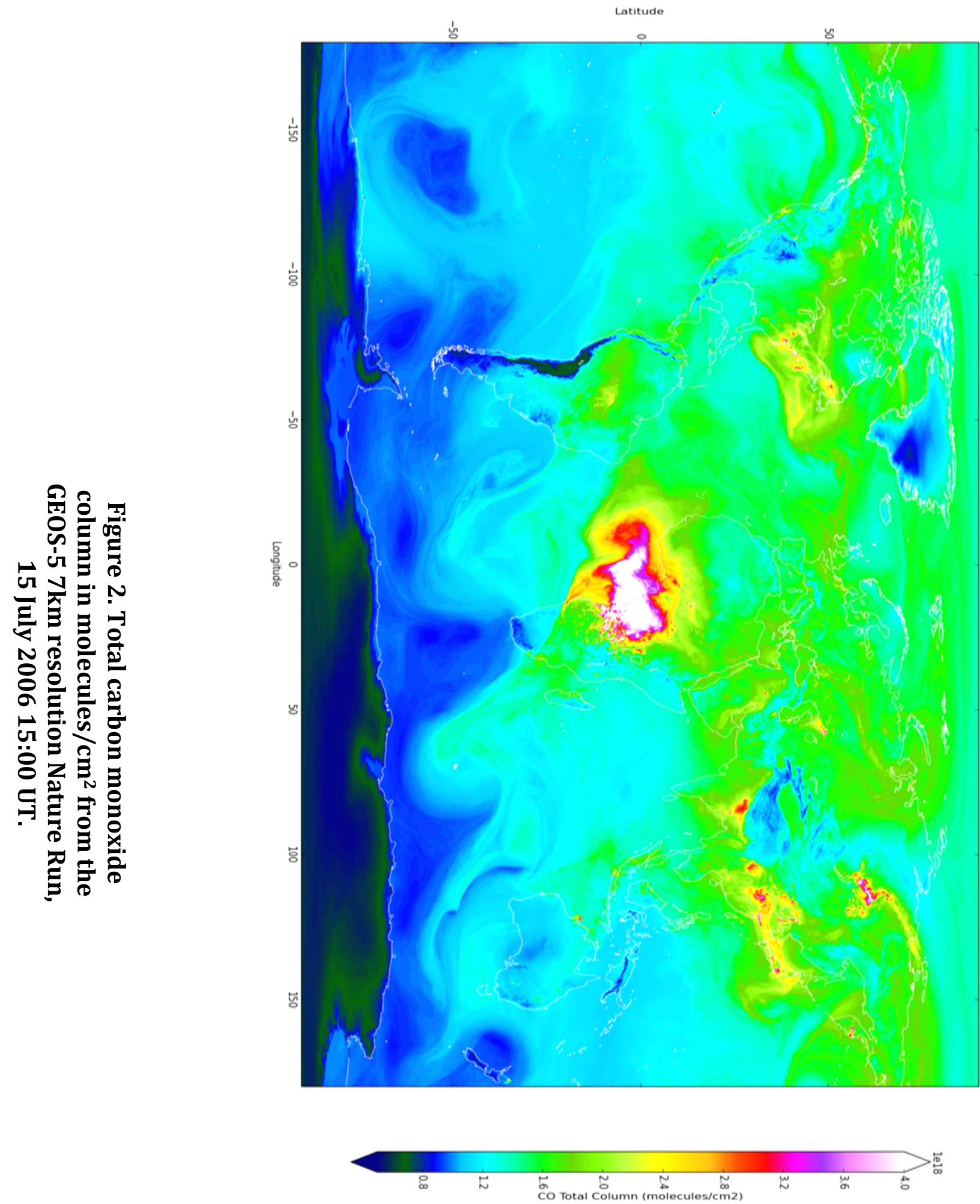
a)

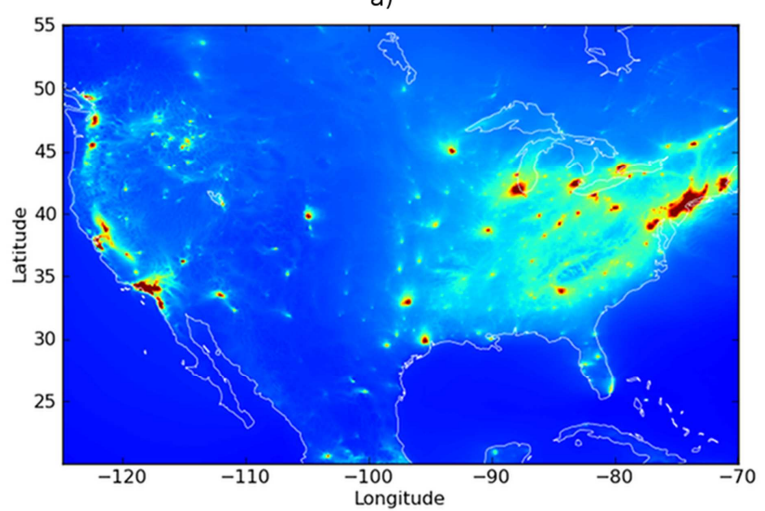

b)

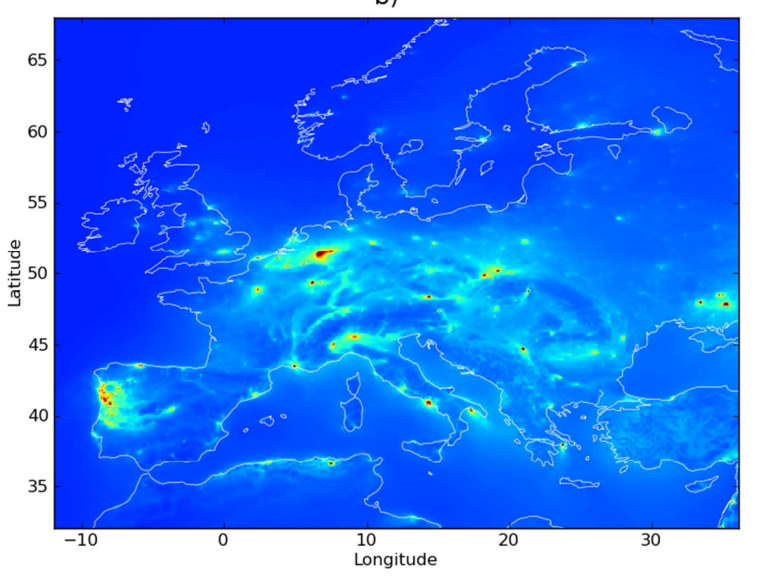

c)

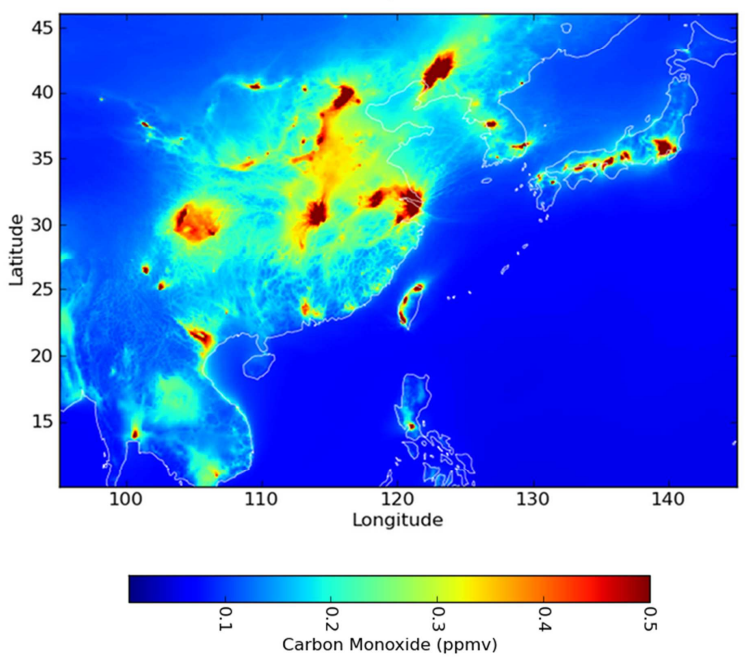

916

917

918

919

Figure 3. Surface CO time average during July 2006 over (a) North America, (b) Europe, and (c) Asia.

920 

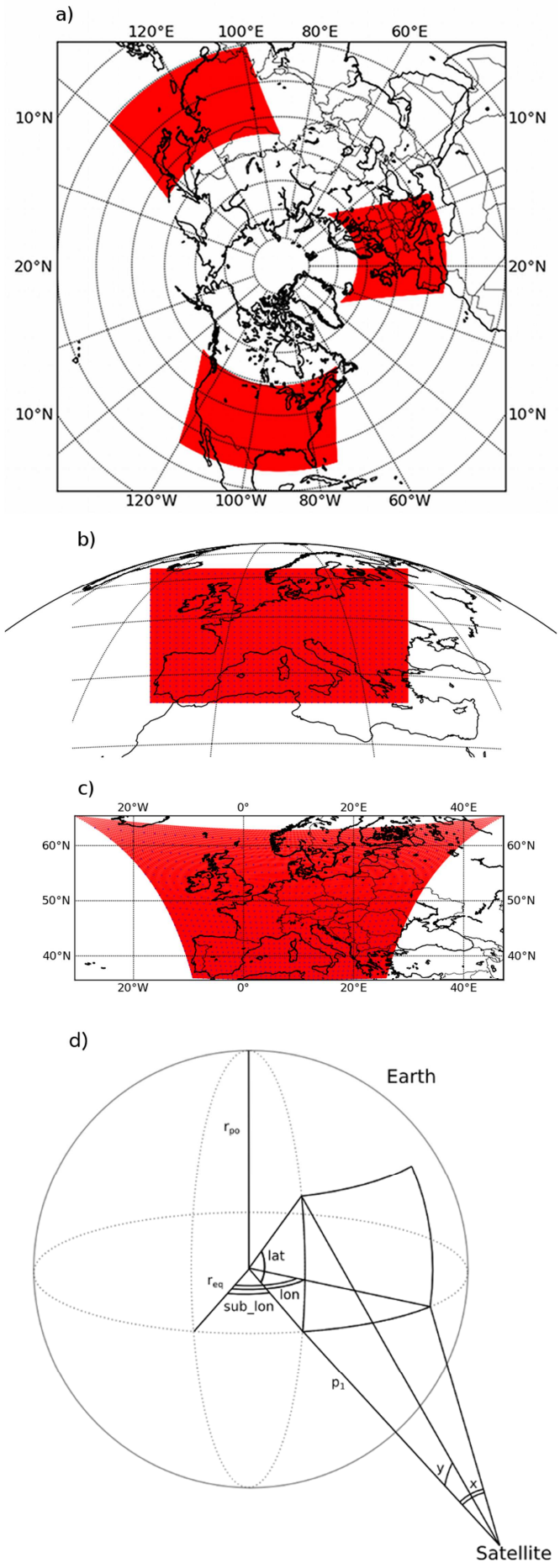

Figure 4. a) Geostationary constellation measurement domain a) Polar projection. b) GEO-EU domain in a geostationary projection, red dots are the full resolution footprints, purple dots are plotted every $100^{\text {th }}$ pixels. c) is the same as b) but in an equidistant latitude-longitude cylindrical projection. d) Geometrical sketch of the geostationary projection. 

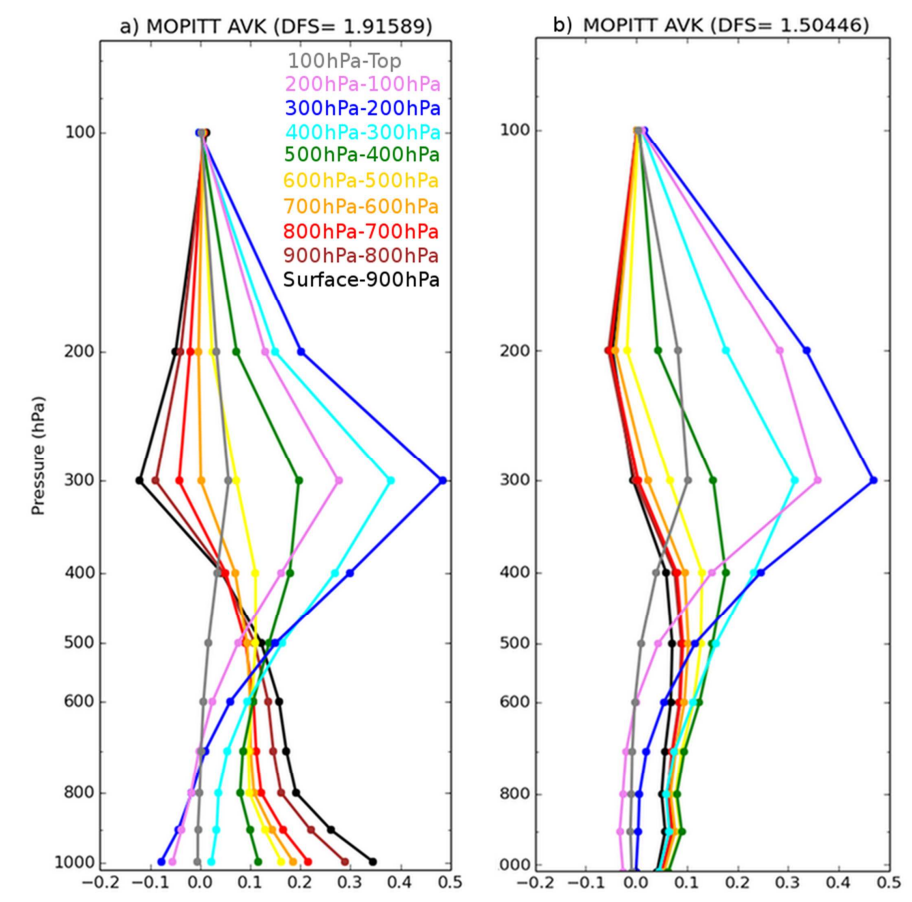
panel: multispectral day/land AK. Right panel: night/land or sea AK. 

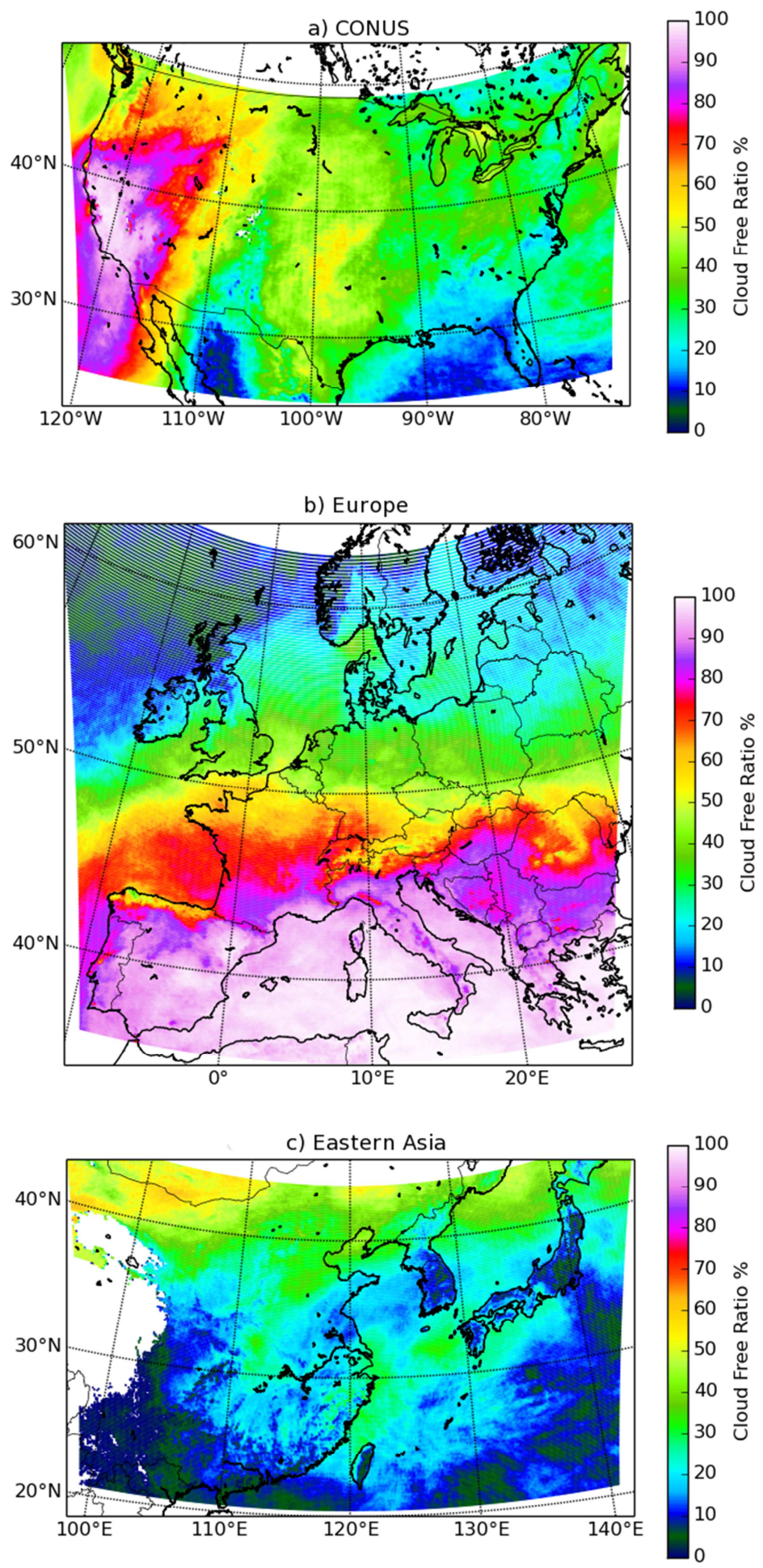
2006. 

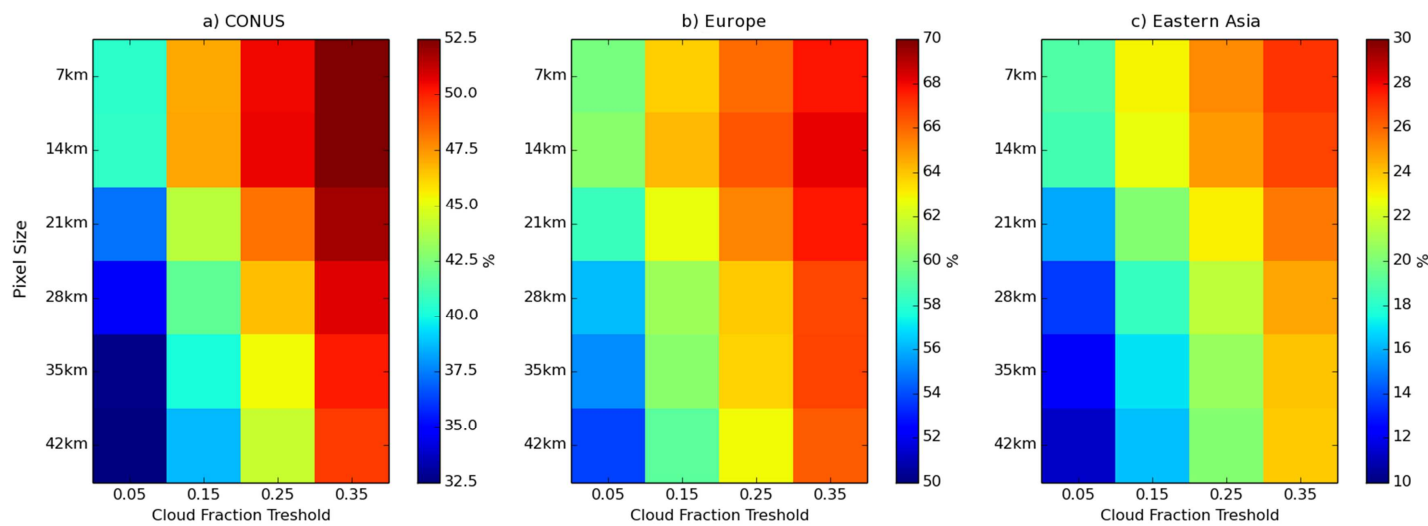

Figure 7. Sensitivity matrices of the average cloud free ratio (in \%) for pixel size versus cloud fraction threshold.
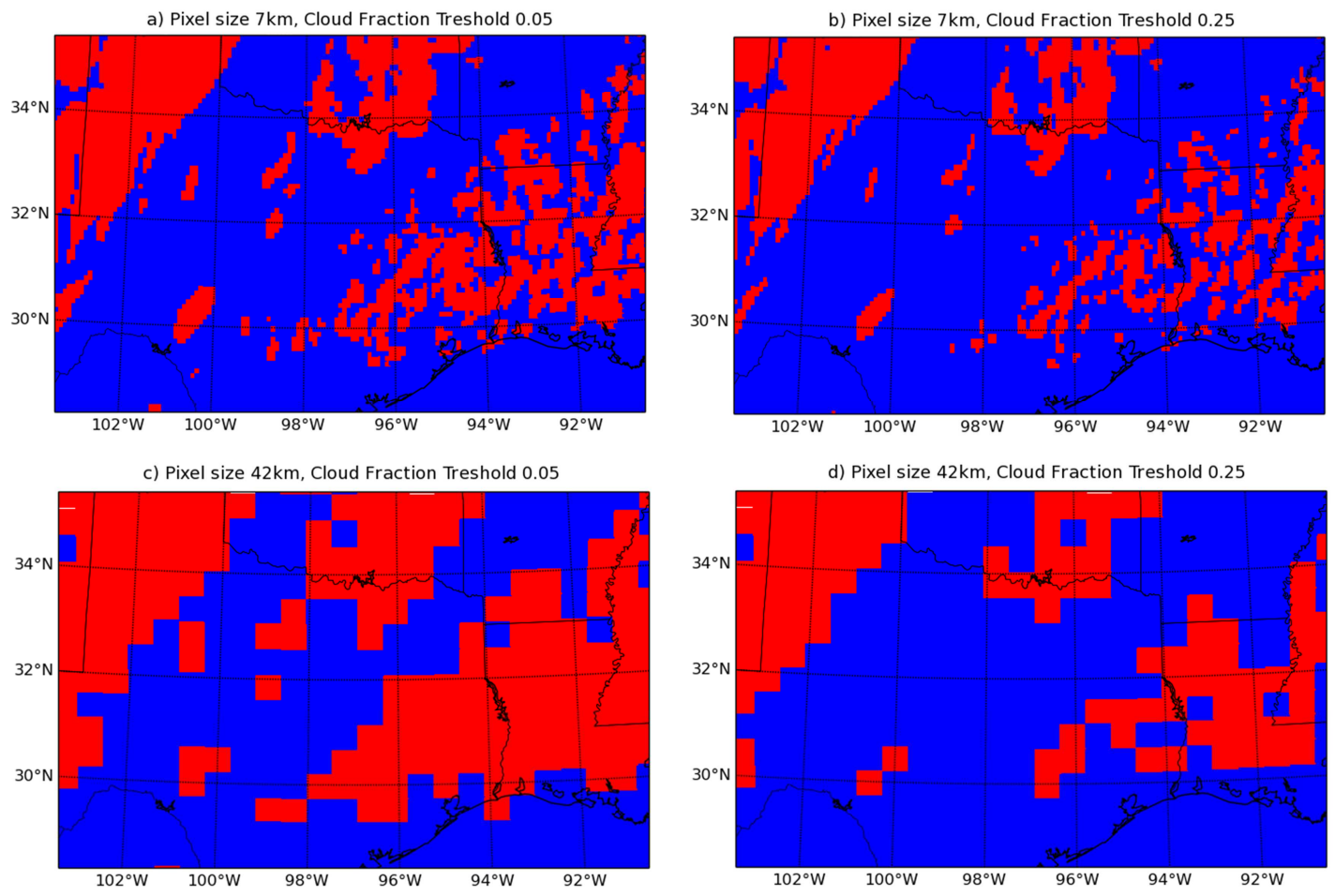

Figure 8. Examples of cloud detection and ratio of observed area for two different cloud fraction thresholds and two different pixel sizes. Red are cloud contaminated pixels and blue are cloud free pixels. Performed over South East CONUS 5 July 2006 00UT. 

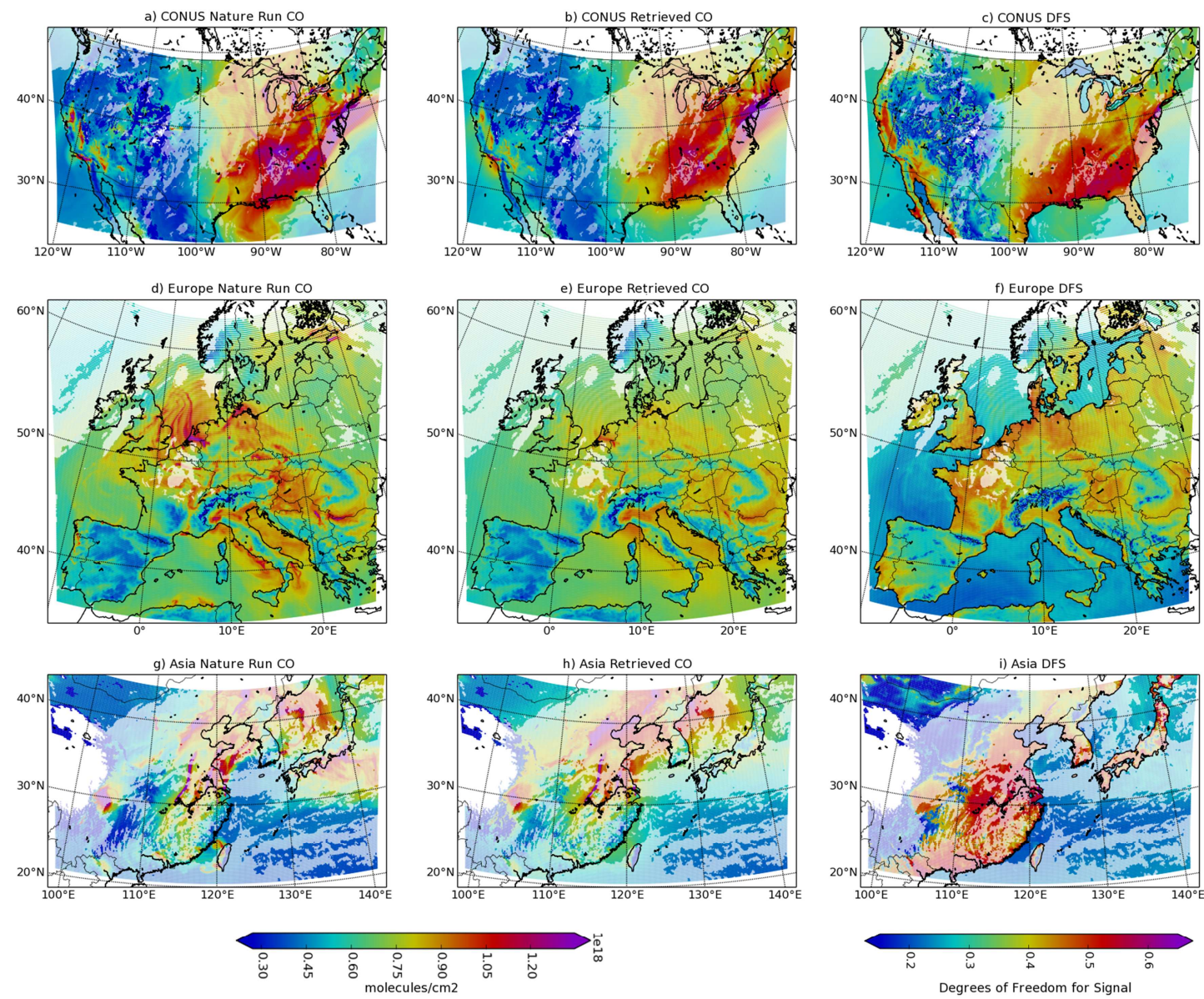

948

949

950

951

952

953

954

955

956

Figure 9. Snapshots of the Nature Run surface to $700 \mathrm{hPa}$ partial column (a, d, g). Corresponding retrieved partial column $(b, e, h)$ and corresponding degrees of freedom for signal (DFS) for surface to $700 \mathrm{hPa}$ (c, f, j). Snapshots are captured at daytime but different dates following regions: 4 July 2006 02UT CONUS, 14 July 2006 10UT Europe, 22 July 2006 18UT Eastern Asia.

Deep colors are the cloud-free pixels. Faded colors represent cloudcontaminated pixels that are not used in further processing. 


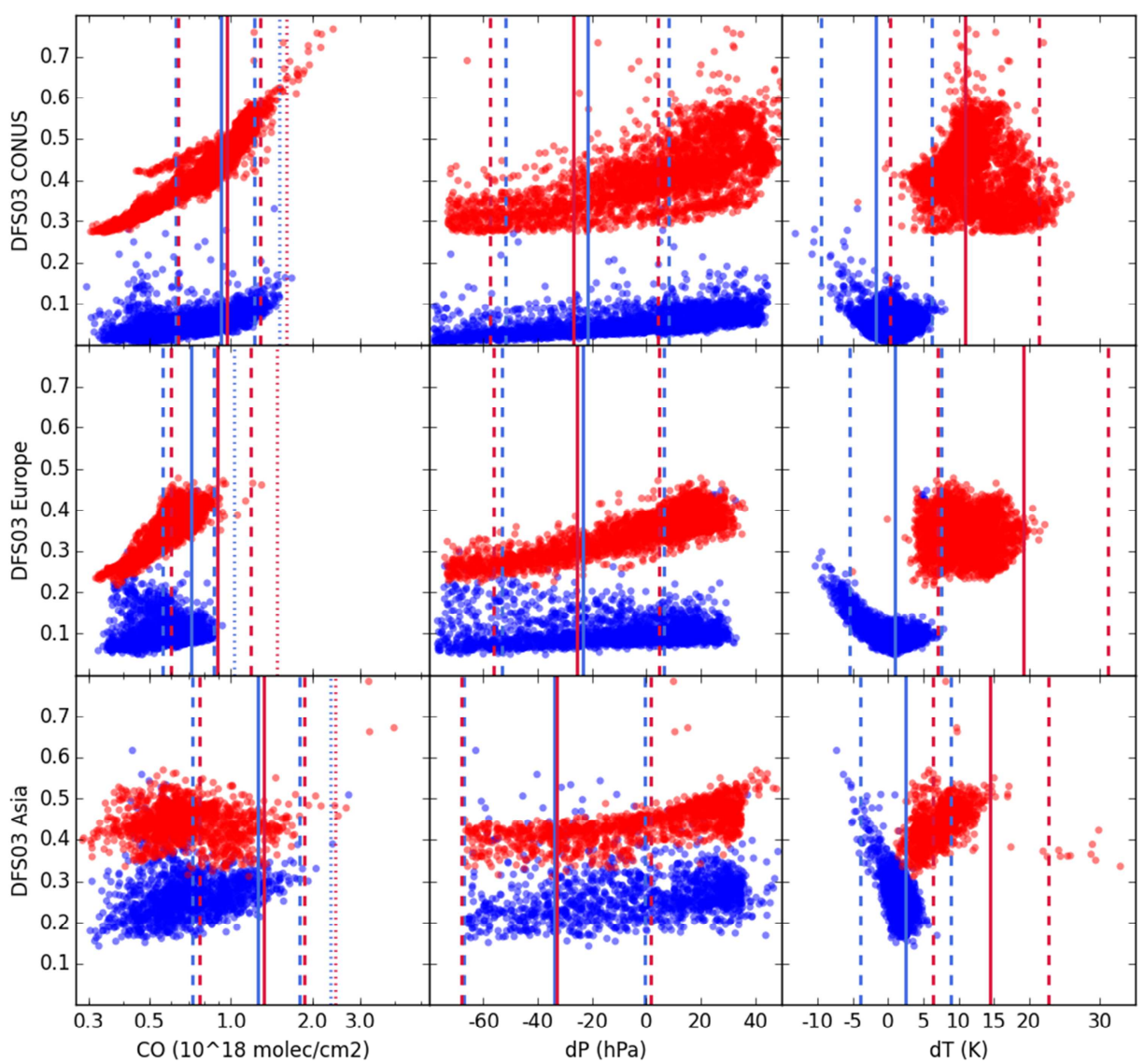

Figure 10. Scatter plots showing variation of degrees of freedom for signal of surface to $\mathbf{7 0 0} \mathrm{hPa}$ versus predictors with highest impacts to the multi-linear regression fit (see table 2 and text for details). Red are day-time values (3pm

local time) and blue are night-time values (3am local time) 5 July 2006.

Vertical solid lines indicate the mean value of the distribution used to build the training sets and dashed lines indicate associated $\pm \sigma$ (standard deviation). Dotted lines indicate associated $+2 \sigma$ for $\mathrm{CO}$ training set. 
a) CONUS

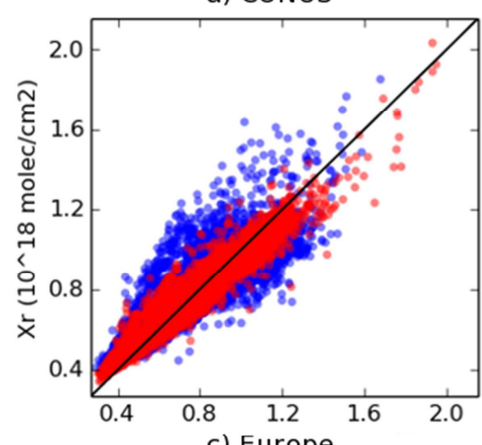

c) Europe

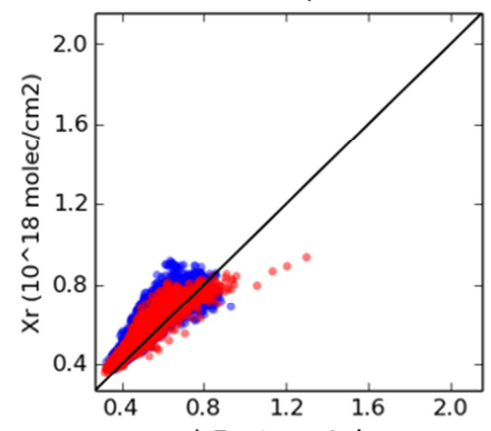

e) Eastern Asia

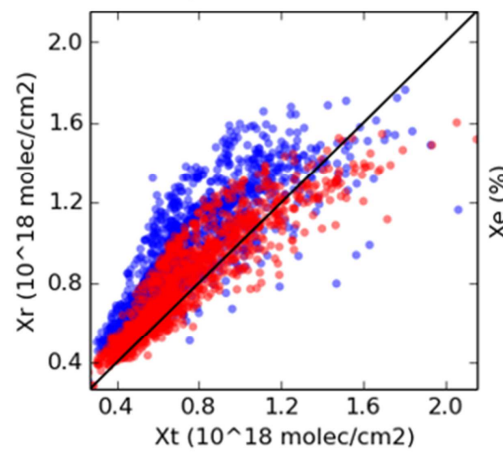

b) CONUS

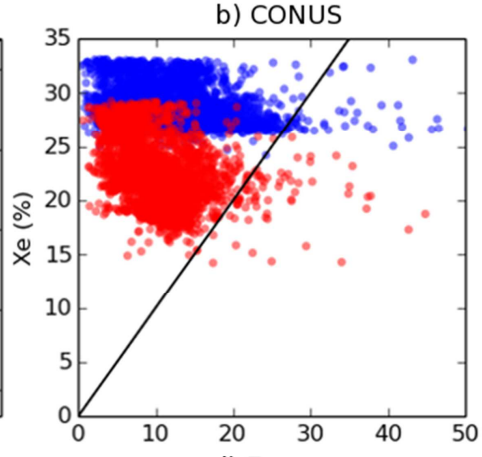

d) Europe

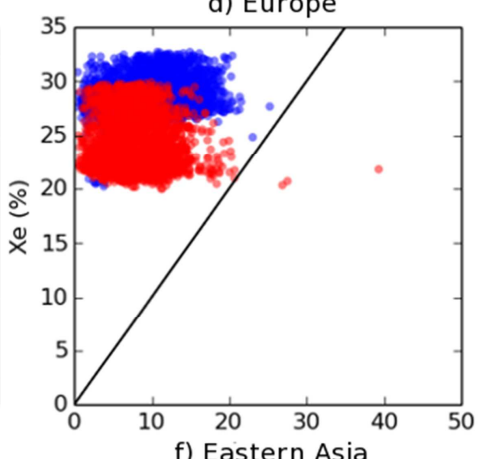

f) Eastern Asia

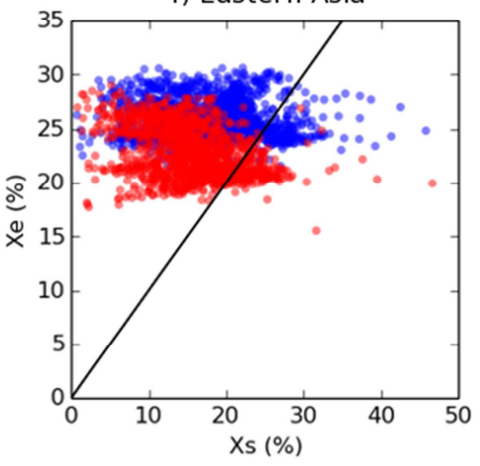

965

966

967

968

969
Figure 11. Left panels: scatter plots of Nature run surface- $700 \mathrm{hPa}$ partial columns (Xt) versus corresponding retrieved partial columns (Xr). Right panels: Smoothing error (Xs) versus corresponding retrieved error (Xe). Dates are the same as described in figure 10. 

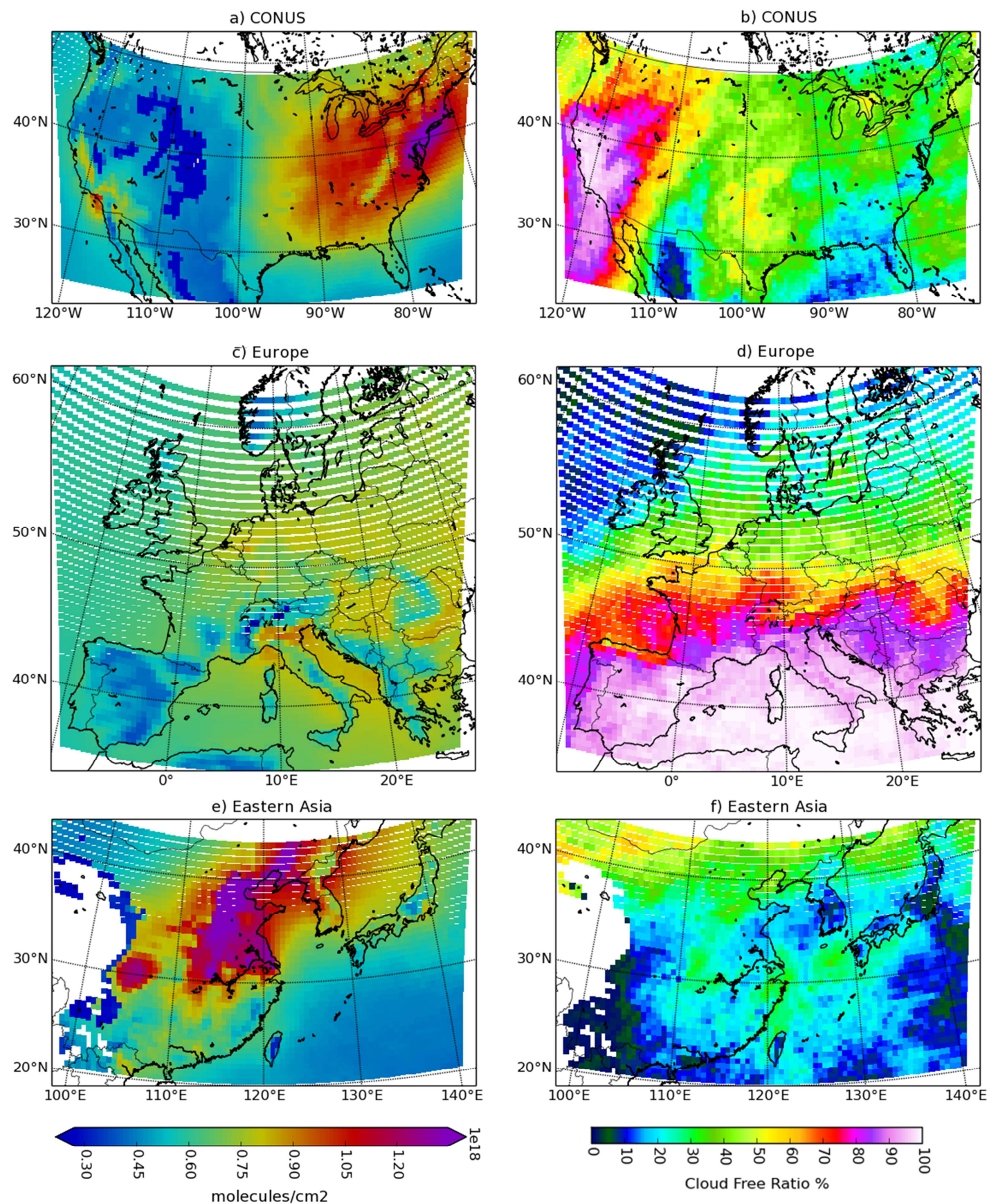

Figure 12. Low-resolution observation simulations used for the assimilation runs. Left panels: July 2006 average retrieved C0 surface-700 hPa partial column. Right panels: Cloud free ratio for July 2006. 